\title{
DESIGN a solar hybrid air conditioning compressor system
}

\author{
M. Khalaji Assadi ${ }^{1}$, S. I. Gilani ${ }^{1}$ and T. C. Jun Yen ${ }^{1, a}$ \\ ${ }^{1}$ Mechanical Engineering Department, Universiti Teknologi PETRONAS, 32610 Bandar Seri Iskandar, Perak Darul Ridzuan, Malaysia
}

\begin{abstract}
To develop and integrate solar hybrid system into conventional air conditioning system which provides the same cooling load with considerably less electricity demand. Solar evacuated tube and DC compressor are used for compressing the refrigerant in an air conditioning system, thus effectively reducing the air conditioning electricity consumption by up to $45 \%$. For the flow through type selected geometry of the designed evacuated U-tube collector, a three dimensional simulation and analysis of the thermal performance was done, using the solar ray-tracing model provided by the ANSYS-FLUENT software.
\end{abstract}

\section{Introduction}

The demand of air conditioning has greatly increased since the last decade due to the effect of climate change and global warming. For instance, two-thirds of residents in Malaysia have air conditioners [1]. Malaysia is among the most enthusiastic developing country to promote utilization of renewable energy. Malaysia as a tropical country with average solar radiation of $4500 \mathrm{Wh} / \mathrm{m}^{2}$ per day, has endless potential in solar energy [2]. High fuel price and electric tariff makes conventional air conditioner not economical in the long run. Furthermore, generating electricity from fossil fuel emits greenhouse gases and worsen the global warming. This paper presents the investigation into the feasibility of solar assisted vapour compression air conditioning system in providing thermal comfort in Malaysia. Solar energy is harvested through solar collector which provides part of compression pressure by heating the refrigerant under constant volume, thus reducing energy consumption by lowering the load on the electric compressor. Computational Fluid Dynamics (CFD) approach has become a significant tool, to investigate the performance and behaviour of heat transfer phenomena.

The objectives of this study are to design and integrate solar hybrid system into conventional air conditioning system, to reduce air conditioning electricity consumption by up to $45 \%$, and to reduce electricity peak load during the day.

\section{Literature Review}

\subsection{Solar Hybrid Air Conditioning System}

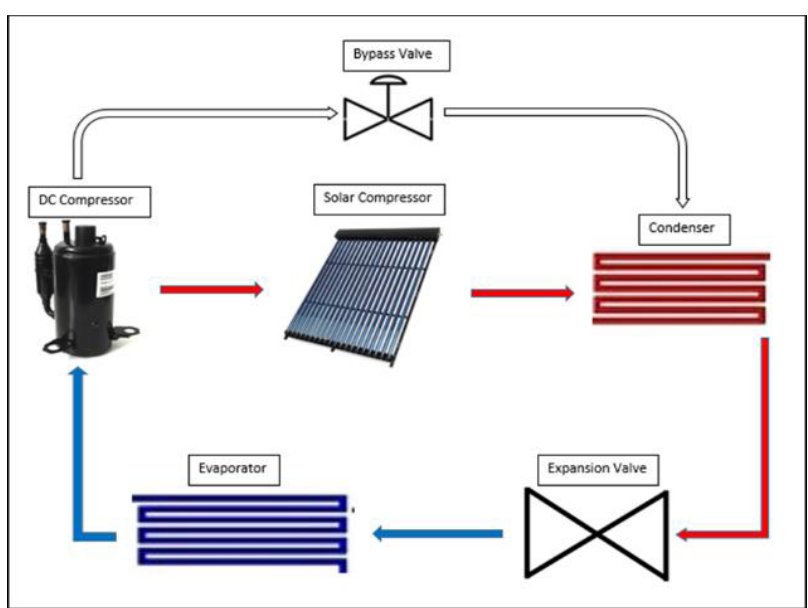

Figure 1. Solar Hybrid Air Conditioning System [3]

Figure 1 shows the evacuated tube solar collector is installed between the compressor and condenser. The solar collector consists of high efficient vacuum tube which provides part of compression pressure and heating by further superheating the refrigerant. The higher pressure and larger temperature difference enhance the condensation process in the condenser, resulting in high pressure liquid refrigerant. This configuration greatly reduces energy consumption by reducing the load on electric compressor.

Furthermore, the alternating current (AC) compressor is replaced with high efficiency direct current (DC) compressor which consumes considerably less energy at the same load compared to AC compressor [4]. DC compressor is powered by high torque brushless motor

\footnotetext{
${ }^{a}$ Corresponding author: thomas92@outlook.com
} 
which is smaller in size and able to operate at variable speed.

\subsection{Refrigerant Cycle}

During refrigeration process, the refrigerant experiences huge change in thermodynamic properties and involves heat energy transfer to the surroundings through the heat exchangers [5]. During the operation of a vapour compression refrigeration system, the following processes occurs as shown in Figure 2.

Process 1-2s: Compression

A reversible, adiabatic (isentropic) compression of the refrigerant. The saturated vapour at state 1 is superheated to state 2 .

$$
w_{c}=h_{2 s}-h_{1}
$$

Process 2s-3: Condensation

An internally, reversible, constant pressure heat rejection in which the refrigerant is de-superheated and then condensed to a saturated liquid at state point 3 .

$$
q_{h}=h_{2 s}-h_{3}
$$

Process 3-4: Throttling and expansion

An irreversible throttling process in which the temperature and pressure decrease at constant enthalpy.

$$
h_{3}=h_{4}
$$

Process 4-1: Evaporation

An internally, reversible, constant pressure heat interaction in which the refrigerant is evaporated to a saturated vapour at state point 1 .

$$
q_{L}=h_{1}-h_{4}
$$

The thermal efficiency of the cycle can be calculated as:

$$
\eta=\frac{q_{\text {evap }}}{w_{\text {comp }}}=\frac{h_{1}-h_{4}}{h_{2 s}-h_{1}}
$$

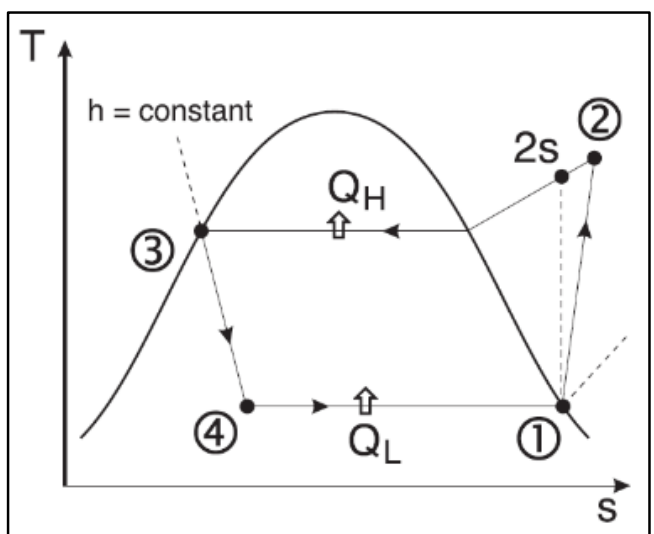

Figure 2. T-s diagram of vapour compression refrigeration cycle [6]

The conventional air conditioning system uses R22 as the refrigerant and operates on an ideal vapour compression refrigeration cycle between $550 \mathrm{kPa}$ and $1700 \mathrm{kPa}$. The ideal refrigeration cycle parameter using $\mathrm{R} 22$ refrigerant is shown in Table 1.
Table 1. Ideal Refrigeration Cycle Parameter - R22 Refrigerant

\begin{tabular}{|l|l|l|l|l|}
\hline State & $\mathbf{1}$ & $\mathbf{2}$ & $\mathbf{3}$ & $\mathbf{4}$ \\
\hline $\begin{array}{l}\text { Pressure, P } \\
\text { (kPa) }\end{array}$ & 550 & 1700 & 1700 & 550 \\
\hline $\begin{array}{l}\text { Temperatur } \\
\text { e, T ('C) }\end{array}$ & 10.00 & 69.20 & 40.00 & 3.09 \\
\hline $\begin{array}{l}\text { Enthalpy, h } \\
\text { (kJ/kg) }\end{array}$ & 411.3 & 440.9 & 249.6 & 249.6 \\
\hline $\begin{array}{l}\text { Entropy, s } \\
\text { (kJ/K-kg) }\end{array}$ & 1.765 & 1.765 & 1.166 & 1.180 \\
\hline Quality & $\begin{array}{l}\text { Superhe } \\
\text { ated } \\
\text { vapour }\end{array}$ & $\begin{array}{l}\text { Superhe } \\
\text { ated } \\
\text { vapour }\end{array}$ & $\begin{array}{l}\text { Subcool } \\
\text { ed liquid }\end{array}$ & 0.227 \\
\hline COP & COP $=\frac{h_{1}-h_{4}}{h_{2}-h_{1}}=\frac{411.3-249.6}{440.9-411.3}=5.46$ \\
\hline
\end{tabular}

\subsection{Evacuated Tube Solar Collector}

The solar collector provides part of compression pressure by heating the refrigerant under constant volume. Ideal gas law states that $P V=n R T$, where $P$ is absolute pressure of gas, $V$ is volume of gas, $n$ is number of moles of gas, $R$ is ideal gas constant, and $T$ is absolute temperature of gas. During the $2^{\text {nd }}$ stage compression, $V, n$, and $R$ are kept constant, deriving the ideal gas law into $\frac{P_{1}}{T_{1}}=\frac{P_{2}}{T_{2}}$, where $P_{1}$ is the input pressure, $T_{1}$ is input temperature, $P_{2}$ is the output pressure, and $T_{2}$ is output temperature. Therefore, the higher the temperature of solar collector, the higher the pressure of refrigerant.

Evacuated tube solar collectors consists of series of glass tubes which has the air evacuated out, creating a vacuum between the glass tube surface and absorber surface. The vacuum layer eliminates heat loss through conduction and convection, leaving radiation as the only heat loss mechanism [7]. Figure 3 shows the thermal network for U-tube evacuated solar collector.

U-tube evacuated solar collector consists of long copper tube which directs the refrigerant flow through the evacuated tube. This allows a greater heat exchanging area which is highly desirable due to the low thermal conductivity of refrigerant vapour.

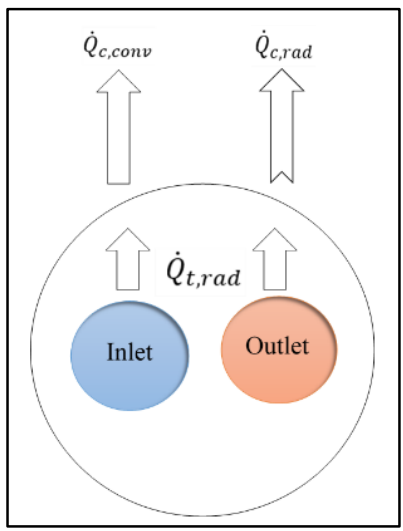

Figure 3. Thermal network for U-tube evacuated solar collector 


\section{Methodology}

In this project, five York Cooling King L Series conventional air conditioner model with capacity ranging from $10000 \mathrm{btu} / \mathrm{h}$ to $24000 \mathrm{btu} / \mathrm{h}$ are selected for analysis.

Table 2. York Cooling King L Series (York Air Conditioner

\begin{tabular}{|l|l|l|l|l|l|}
\hline Model & $\mathbf{1}$ & $\mathbf{2}$ & $\mathbf{3}$ & $\mathbf{4}$ & $\mathbf{5}$ \\
\hline $\begin{array}{l}\text { Cooling } \\
\text { Capacity } \\
\text { (Btu/h) }\end{array}$ & 10000 & 13000 & 18000 & 19500 & 24000 \\
\hline $\begin{array}{l}\text { Power } \\
\text { (W) }\end{array}$ & 815 & 1015 & 1360 & 1540 & 2230 \\
\hline $\begin{array}{l}\text { Current } \\
\text { (A) }\end{array}$ & 4.38 & 5.36 & 7.16 & 8.12 & 12 \\
\hline $\begin{array}{l}\text { Compress } \\
\text { or Power } \\
\text { (W) }\end{array}$ & 735.0 & 915.0 & 1222.5 & 1387.5 & 2006.3 \\
\hline $\begin{array}{l}\text { Refrigera } \\
\text { nt }\end{array}$ & $\mathrm{R} 22$ & $\mathrm{R} 22$ & $\mathrm{R} 22$ & $\mathrm{R} 22$ & $\mathrm{R} 22$ \\
\hline COP & 3.99 & 4.16 & 4.31 & 4.12 & 3.51 \\
\hline
\end{tabular}

This project involves the design of solar hybrid air conditioning system which starts from identifying the position of solar compressor and modifications needed. Next, the operating parameter of the refrigeration cycle to achieve targeted energy savings is determined. The evacuated tube solar collector which acts as solar compressor is CFD simulated to heat up the refrigerant up to $160^{\circ} \mathrm{C}$ based on solar radiation data at Universiti Teknologi Petronas. Then, the condenser is redesign to be able to cool down the refrigerant to $40^{\circ} \mathrm{C}$ from up to $160^{\circ} \mathrm{C} .5$ models covering wide range of cooling capacity is chosen to provide comparison of the energy savings achievable and suit the needs of consumers. Generally the energy savings increases with the cooling capacity.

ANSYS-FLUENT software is used extensively to determine the required length of evacuated tube solar collector and refrigerant output temperature at different hours in a day. The results are then compared with theoretical calculations to determine the energy saving performance. Meanwhile, the results are compared with experiment of other researchers using actual air conditioner and evacuated tube solar collector to further verify the results.

The major steps involved in simulation are outlining and specifying of the model geometry according to the main design consideration. Discrete Ordinates (DO) Radiation model is used, along with solar loading model which allows inclusion of the effects of solar radiation in the simulation.

The developed evacuated tube solar collector is a Utube flow through type. The flow domain is copper tube, coated with $1 \mathrm{~mm}$ of selective absorber while insulated within circular glass vacuum enclosure. The R22 refrigerant enters the copper tube with mass flow rate ranging from $0.0181 \mathrm{~kg} / \mathrm{s}$ to $0.0435 \mathrm{~kg} / \mathrm{s}$ depending on model. Pressure outlet end is selected. The collector configuration is as shown in Figure 4.

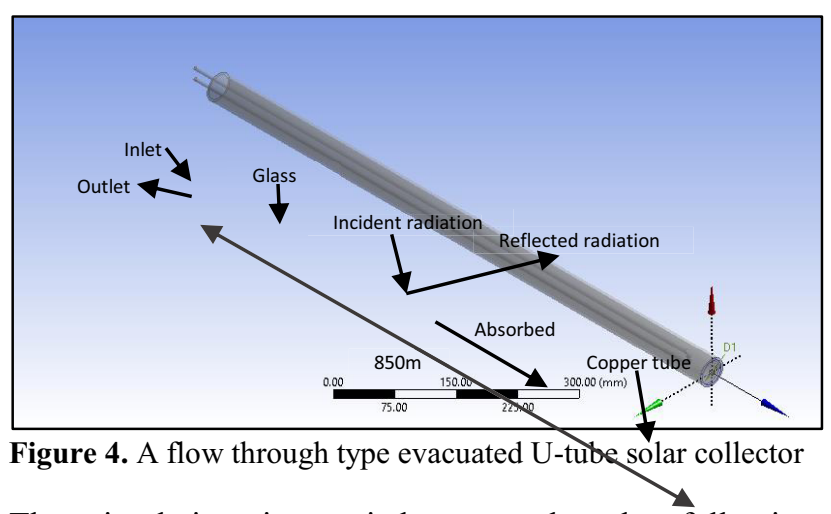

The simulation is carried out under the following assumptions:

i. The refrigerant flow is continuous

ii. The flow is steady and laminar

iii. The selected longitude, latitude and time zone are 100.9797, 4.3864 and +8 at Universiti Teknologi Petronas as solar calculator input

iv. Solar ray tracing with fair weather condition model option is selected

v. Performance is in steady state

vi. The headers provide uniform flow to tubes

vii. Dust and dirt on the collector are negligible

In solar ray-tracing model, the solar radiation heat flux is solved using fair weather condition radiation equations, and then solar radiation load is considered as a heat source term in the energy equation. For coated glazing, the spectral transmissivity and reflectivity at any incident angle are approximated from the normal angle of incidence.

Transmissivity, is given by [8].

$$
T(\theta, \lambda)=T(0, \lambda) \operatorname{Tre} f(\theta)
$$

$$
\begin{aligned}
\operatorname{Tref}(\theta)=a^{0}+ & a^{1} \cos (\theta)+a^{2} \cos \left(\theta^{2}\right)+a^{3} \cos \left(\theta^{3}\right) \\
& +a^{4} \cos \left(\theta^{4}\right)
\end{aligned}
$$

Reflectivity is given by

$$
\begin{gathered}
R(\theta, \lambda)=R(0, \lambda)[1-\operatorname{Rref}(\theta)]+\operatorname{Rref}(\theta) \\
\operatorname{Rref}(\theta)=b^{0}+b^{1} \cos (\theta)+b^{2} \cos \left(\theta^{2}\right)+b^{3} \cos \left(\theta^{3}\right) \\
+b^{4} \cos \left(\theta^{4}\right)
\end{gathered}
$$

Where:

$T(0, \lambda)=$ normal transmissivity

$R(0, \lambda)=$ normal reflectivity

\section{Result and Discussion}

\subsection{Solar Hybrid Vapour Compression Refrigeration Cycle}

The evacuated tube solar collector is installed between the compressor and condenser, providing part of compression pressure and heating by further superheating the refrigerant. Figure 5 shows the parameters of solar hybrid vapour compression refrigeration cycle at maximum 
energy saving where the refrigerant temperature achieved $160^{\circ} \mathrm{C}$ at the solar collector outlet. The electric DC compressor workload is significantly reduced due to the lower output pressure of $1280 \mathrm{kPa}$ compared to the original $1700 \mathrm{kPa}$. Point $\mathrm{X}$ and 2 are the respective design parameters at electric compressor outlet and solar compressor outlet. Since Point 2 is the solar compressor outlet, the parameters varies with the availability of solar radiation. Point $\mathrm{X}$ and 2 are closely related, thus both are precisely controlled so that electric compressor will supply additional compression power during low solar radiation period. Point 1,3 and 4 are kept constant as the conventional system to achieve the same cooling capacity.

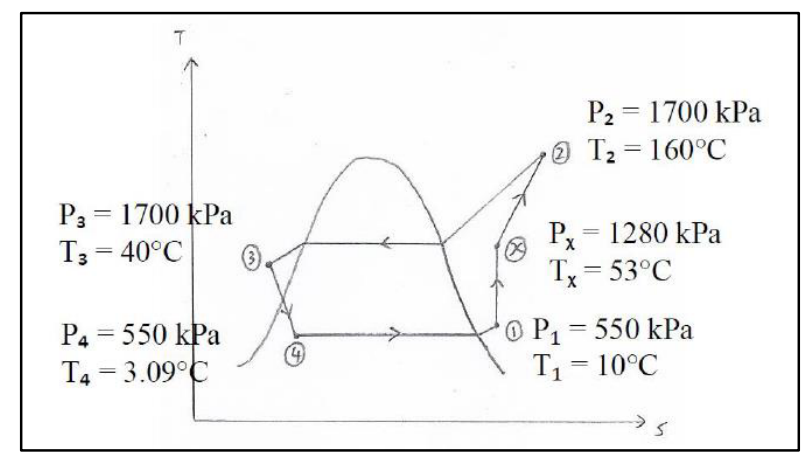

Figure 5. T-s diagram of solar hybrid vapour compression refrigeration cycle

Process 1-x: Electric DC compressor

Process x-2: Solar compressor

Process 2-3: Condenser

Process 3-4: Expansion valve

Process 4-1: Evaporator

\subsection{Solar Radiation at Universiti Teknologi Petronas}

The solar radiation data at Universiti Teknologi Petronas is generated through Solar Calculator in ANSYS software with longitude, latitude and time zone as 100.9797, 4.3864 and +8 respectively. Solar ray tracing with fair weather condition model option is also selected. The solar radiation at the studied area increases rapidly from $7 \mathrm{am}$ and peaks at around $12 \mathrm{pm}$ to $2 \mathrm{pm}$ and begins to decrease until sunset at around $7 \mathrm{pm}$.

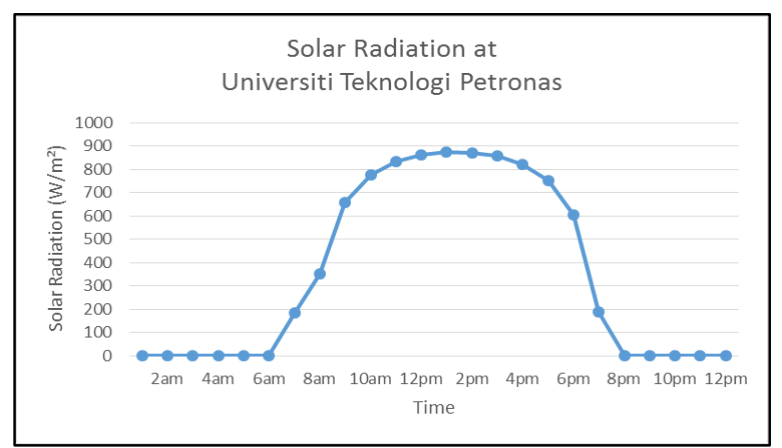

Figure 6. Solar Radiation at Universiti Teknologi Petronas

\subsection{Energy Saving}

The higher the refrigerant temperature, the higher the system energy saving, thus contributing to lower power consumption. However, the maximum energy saving is limited at $160^{\circ} \mathrm{C}$ of refrigerant temperature at condenser inlet. The designated condenser is unable to remove any excess heat energy from the refrigerant at temperature higher than $160^{\circ} \mathrm{C}$. In short, the solar compressor provide energy saving when refrigerant temperature at condenser inlet is in the range of $69.2^{\circ} \mathrm{C}$ up to $160^{\circ} \mathrm{C}$. At refrigerant temperature lower than $69.2^{\circ} \mathrm{C}$, the energy saving is solely supported by the highly efficient DC compressor.

Energy savings are calculated by comparing the change in enthalpy of refrigerant through the electric compressor of both conventional and solar hybrid system. Compressor energy saving, $\mathrm{S}$ is given by

$$
S=1-\frac{h_{x a}-h_{1}}{h_{2 a}-h_{1}} \times 100 \%
$$

Where $h_{2 a}$ and $h_{x a}$ is refrigerant enthalpy at electric compressor outlet for conventional system and solar hybrid system respectively. Figure 7 shows the compressor energy saving at different refrigerant temperature.

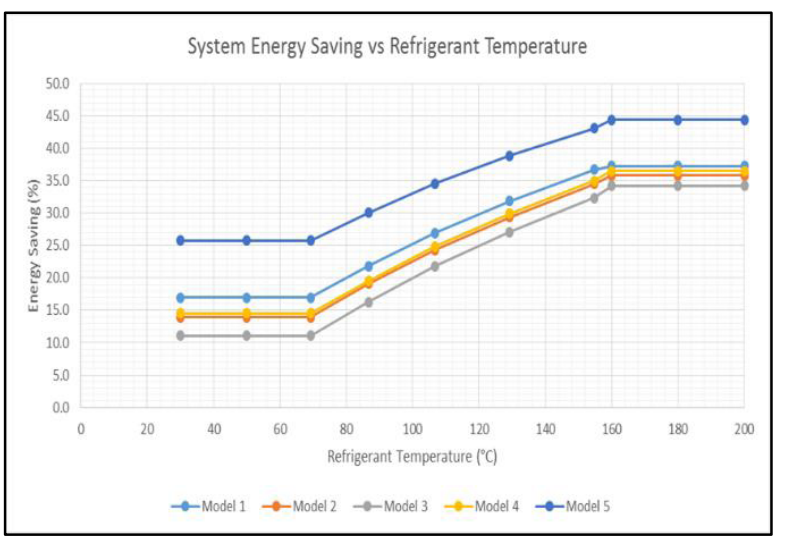

Figure 7. Graph of System Energy Saving vs Refrigerant Temperature at Condenser Inlet

During day time, the energy saving is achieved by both DC compressor and solar compressor. The energy saving increases rapidly from $7 \mathrm{am}$ and peaks at around $10 \mathrm{am}$ to $4 \mathrm{pm}$ and begins to decrease until night time. During night time, the absence of solar radiation means energy saving is only contributed by the DC compressor.

During daytime, Model 5 can achieve the highest maximum energy saving of $44.4 \%$, followed by Model 1 , 2,3 and 4 with energy saving of $37.2 \%, 35.8 \%, 34.2 \%$ and $36.5 \%$ respectively. During nighttime, DC compressor manages energy saving of $25.7 \%$ for Model 5 , followed by Model 1, 2, 3 and 4 with energy saving of $17.0 \%, 13.9 \%$, $11.1 \%$ and $14.5 \%$ respectively. Figure 8 and 9 shows the system energy saving and system power consumption versus time. 


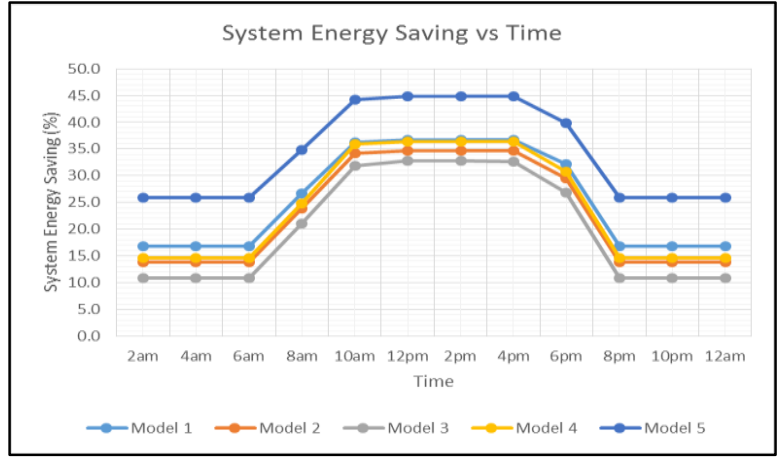

Figure 8. Graph of System Energy Saving vs Time

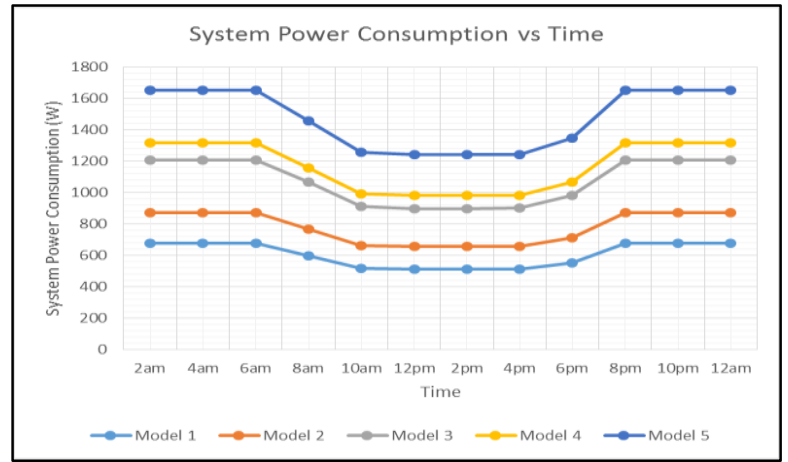

Figure 9. Graph of System Power Consumption Saving vs Time

\subsection{Evacuated Tube Solar Collector Sizing}

The ANSYS simulation is run extensively using the following governing equations with continuous iterations until the program is converged to determine the size of evacuated tube solar collector required to achieve at least $160^{\circ} \mathrm{C}$ of refrigerant temperature in each of the air conditioner model.

\subsubsection{Heat loss coefficient:}

i. Radiation coefficient between the copper tube and the glass cover:

$$
h_{r, t-c}=\frac{\sigma\left(T_{t}^{2}+T_{c}^{2}\right)\left(T_{t}+T_{c}\right)}{\frac{1}{\varepsilon_{t}}+\frac{1}{\varepsilon_{c}}-1}
$$

ii. Radiation coefficient for the glass cover to the air:

$$
h_{r, c-a}=\varepsilon_{c} \sigma\left(T_{c}^{2}+T_{s}^{2}\right)\left(T_{c}+T_{s}\right)
$$

iii. Convection coefficient for the glass cover to the air:

$$
h_{c, c-a}=\frac{k}{D_{c}} N u
$$

Rayleigh number,

$$
R a=\frac{g \beta\left(T_{c}-T_{a}\right) D_{c}^{3}}{v^{2}} \operatorname{Pr}
$$

Nusselt number,

$$
N u=\left[0.6+\frac{0.387 R a^{\frac{1}{6}}}{\left[1+\left(\frac{0.559}{P r}\right)^{\frac{9}{16}}\right]^{\frac{8}{27}}}\right]^{2}
$$

iv. Top loss coefficient:

$$
U=\left(\frac{1}{\left(A_{t}\right)\left(h_{r, t-c}\right)}+\frac{1}{\left(A_{c}\right)\left(h_{r, c-a}+h_{c, c-a}\right)}\right)^{-1}
$$

v. Glass cover temperature

$T_{c}=T_{t}-\frac{U\left[\frac{h_{r, c-a}}{h_{r, c-a}+h_{c, c-a}}\left(T_{t}-T_{s}\right)+\frac{h_{c, c-a}}{h_{r, c-a}+h_{c, c-a}}\left(T_{t}-T_{a}\right)\right]}{\left(A_{t}\right) h_{r, t-c}}$

\subsubsection{Rate of energy balance equation:}

$$
\begin{gathered}
h_{r, t-c}=h_{r, c-a}+h_{c, c-a} \\
\frac{\sigma A_{t}\left(T_{t}^{4}-T_{c}^{4}\right)}{\frac{1}{\varepsilon_{t}}+\frac{1-\varepsilon_{c}}{\varepsilon_{c}}\left(\frac{D_{t}}{D_{c}}\right)}=\varepsilon_{c} \sigma A_{c}\left(T_{c}^{4}-T_{s}^{4}\right)+h_{c, c-a} A_{c}\left(T_{c}-T_{a}\right)
\end{gathered}
$$

Where:

$\varepsilon_{t}=$ copper tube emittance

$\varepsilon_{c}=$ glass cover emittance

$T_{a}=$ ambient temperature $(\mathrm{K})$

$T_{s}=$ sky temperature $(\mathrm{K})$

$T_{t}=$ mean tube temperature $(\mathrm{K})$

$T_{c}=$ glass cover temperature $(\mathrm{K})$

$A_{t}=$ area of absorber tube, $\mathrm{m}^{2}$

$A_{c}=$ area of glass cover, $\mathrm{m}^{2}$

$\sigma=$ Stefan-Boltzman constant $\left(5.67 \times 10^{-8} \mathrm{~W} / \mathrm{m}^{2} \mathrm{~K}^{4}\right)$

The CFD Fluent program is converged with steady state simulation. Figure 4 shows the convergence and contour distribution of model static temperature for the U-tube evacuated solar collector.

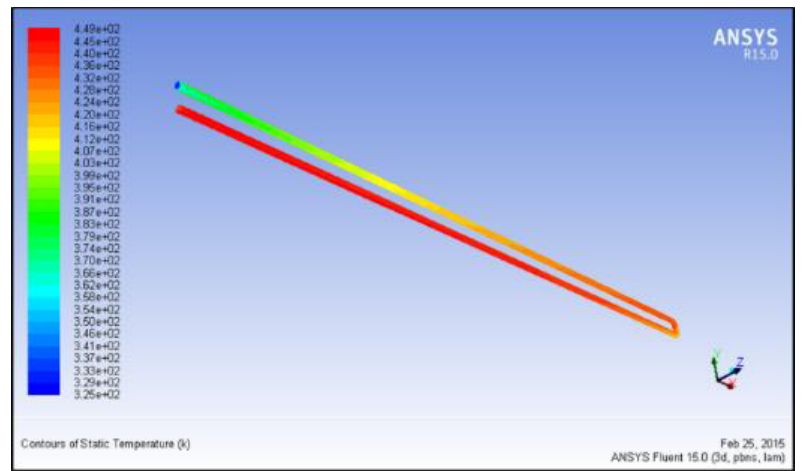

Figure 10. Temperature contour of U-tube evacuated solar collector

The U-tube evacuated tube solar collector consists of a U-shaped copper absorber tube, with $5 \mathrm{~mm}$ inner diameter and $2 \mathrm{~mm}$ thickness. The circular copper tube is covered 
with $1 \mathrm{~mm}$ thickness of selective absorber coating to improve tube absorptivity. The U-tube is insulated with circular glass enclosure with $39 \mathrm{~mm}$ outer diameter and $3 \mathrm{~mm}$ thickness. The headers provide uniform flow to each U-tubes.

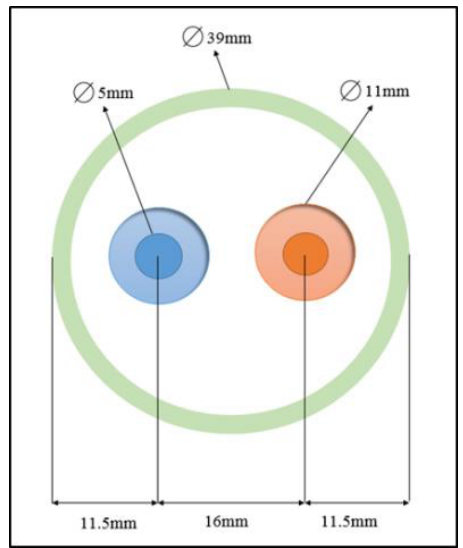

Figure 11. U-tube evacuated tube sizing

The tube length and number of tubes indicating the evacuated tube solar collector sizing for each model is shown in the Table 3:

Table 3. Evacuated tube solar collector sizing

\begin{tabular}{|l|l|l|l|}
\hline & $\begin{array}{l}\text { Tube } \\
\text { Length }(\mathrm{m})\end{array}$ & $\begin{array}{l}\text { Number } \\
\text { of Tubes }\end{array}$ & $\begin{array}{l}\text { Dimension } \\
(\mathrm{W} \times \mathrm{H} \times \mathrm{D}) \\
\mathrm{mm}^{3}\end{array}$ \\
\hline Model 1 & 0.65 & 12 & $580 \times 750 \times 60$ \\
\hline Model 2 & 0.85 & 12 & $580 \times 950 \times 60$ \\
\hline Model 3 & 0.85 & 16 & $780 \times 950 \times 60$ \\
\hline Model 4 & 0.85 & 18 & $875 \times 950 \times 60$ \\
\hline Model 5 & 0.85 & 22 & $1080 \times 950 \times 60$ \\
\hline
\end{tabular}

\subsection{Condenser Sizing}

The condenser need to be $45 \%$ longer, regardless of models, in order to cool down the refrigerant to $40^{\circ} \mathrm{C}$ from up to $160^{\circ} \mathrm{C}$. The extra refrigerant heat is produced by the solar compressor which uses the solar thermal energy to increase the refrigerant pressure. In contrast, the conventional unit only has to cool down the refrigerant temperature from $69.2^{\circ} \mathrm{C}$ to $40^{\circ} \mathrm{C}$. The refrigerant is further subcooled before entering the throttle valve while pressure drop in the extra length of condenser is insignificant and can be neglected [9].

The rate of heat loss in condenser is given by

$$
\dot{Q}=\dot{m}_{r} C_{p}\left(T_{\text {out }}-T_{\text {in }}\right)
$$

Where $\dot{m}_{r}$ and $C_{p}$ represents the mass flow rate and heat capacity of the refrigerant. The condenser length is calculated by comparing the rate of heat loss for both condenser in conventional and solar hybrid system, where the heat loss coefficient and coil diameter are assumed to be constant. Condenser rate of heat loss is given by

$$
\dot{Q}=h A_{s}\left(T_{s}-T_{a}\right)
$$

Where $T_{s}$ and $T_{a}$ represents the condenser coil surface temperature and ambient air temperature respectively.

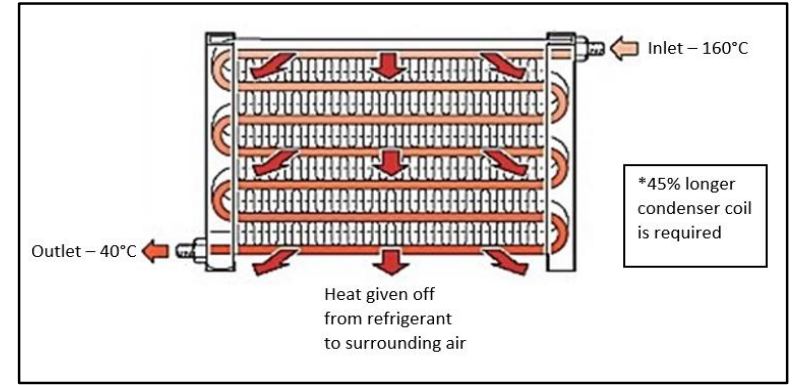

Figure 12. Air Conditioner Condenser Coil

\subsection{Evacuated Tube Solar Compressor Position}

Both electric compressor and solar compressor uses different ways to pressurise the refrigerant. The electric compressor works by mechanically forcing the refrigerant into a smaller volume while the solar collector provides the compression pressure by heating the refrigerant under constant volume. The study results shown that the solar compressor has to be placed after the electric compressor.

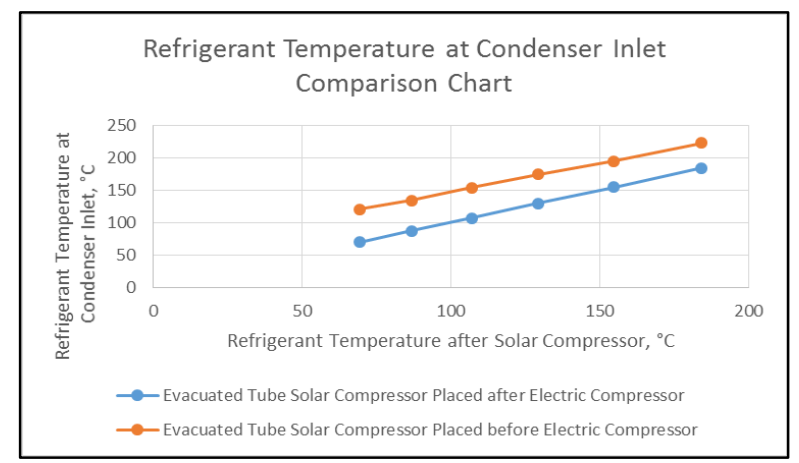

Figure 13. Refrigerant temperature comparison for different solar compressor position

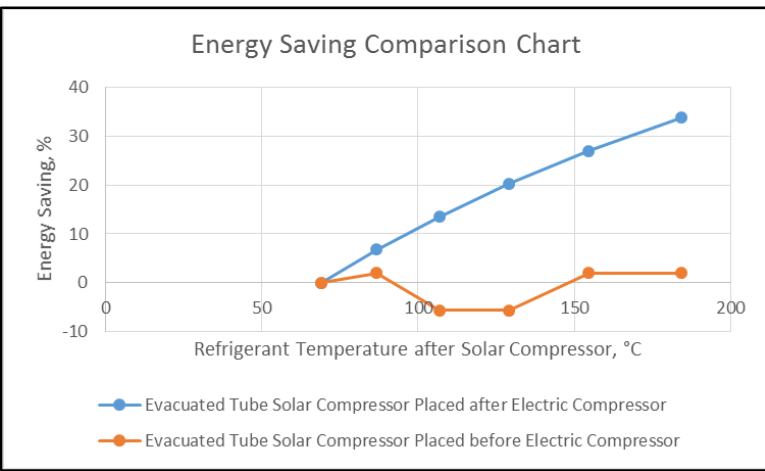

Figure 14. Compressor energy saving comparison for different solar compressor position

Both Figure 13 and Figure 14 confirms the advantages of placing solar compressor after electric compressor. For comparison, if solar compressor is placed after electric compressor, the refrigerant temperature entering the condenser is significantly lower, which translates to smaller size condenser. Furthermore, in this configuration, the energy saving increases with the refrigerant temperature. On the other hand, placing the solar compressor before electric compressor provides little to no energy saving due to the high refrigerant temperature requirement. 


\section{Conclusion}

Solar air conditioning system is a great innovation which pushes solar energy leaps ahead while promoting positive impact on the environment. This research provides the comprehensive comparison of energy savings achievable for different air conditioner capacity ranging from $10000 \mathrm{btu} / \mathrm{h}$ to $24000 \mathrm{btu} / \mathrm{h}$. The system is able to achieve up to $45 \%$ energy saving during daytime, thus significantly reduces the electricity peak load during the day. Meanwhile, the DC compressor will contribute up to $25 \%$ of energy saving during night time. The main modifications needed are DC compressor, higher capacity condenser and evacuated tube solar collector. In addition, Microsoft Excel spreadsheet is also prepared to facilitate the calculation of refrigerant temperature and energy saving of the system. Thermal storage and photovoltaic system to provide full off grid performance are suggested for future development.

\section{References}

1. Daut I., Adzrie M., Irwanto M., Ibrahim P. and Fitra M. 2013, Solar Powered Air Conditioning System, Thesis, Universiti Malaysia Perlis, Malaysia
2. Borhanazad H., Mekhilef S., Saidur R. and Boroumandjazi G. 2013, Potential application of renewable energy for rural electrification in Malaysia, Thesis, University of Malaya, Malaysia

3. Kalkan N., Young E.A. and Celiktas A. 2011, Solar Thermal Air Conditioning Technology Reducing the Footprint of Solar Thermal Air Conditioning, Thesis, University of Southampton, United Kingdom.

4. Henning H.M. 2007, Solar Assisted Air Conditioning in Buildings, Austria, SpringerVerlag Wien New York.

5. Admiraal D.M. and Bullard C.W. 1993, Heat Transfer in Refrigerator Condensers and Evaporators, Thesis, University of Illinois, Urbana

6. Demma D. 2005, The Pressure-Enthalpy Chart, Report, Parker Hannifin Corporation, Washington

7. Jafarkazemi F. and Abdi H. 2012, Evacuated tube solar heat pipe collector model and associated tests, Thesis, Islamic Azad University, Iran

8. A. F. 2011, Ansys, 14.0 User's Guide, ANSYS Inc.

9. Cengel Y.A. and Ghajar A.J. 2013, Heat and Mass Transfer, Fundamentals and Applications, Singapore, Mc Graw Hill 